\title{
Preservice Teachers' Images of Scientists: Do Prior Science Experiences Make a Difference?
}

\begin{abstract}
This article presents the results of a mixed methods study that used the Draw-a-Scientist Test (DAST) as a visual tool for exploring preservice teachers' beliefs about scientists. A questionnaire was also administered to 165 students who were enrolled in elementary (K-8) and secondary (8-12) science methods courses. Taken as a whole, the images drawn by preservice teachers reflected the stereotype of a scientist as a man with a wild hairdo who wears a lab coat and glasses while working in a laboratory setting. However, results indicated statistically significant differences in stereotypical components of representations of scientists depending on preservice teachers' program and previous science experiences. Post degree students in secondary science methods courses created images of scientists with fewer stereotypical elements than drawings created by students in the regular elementary program.
\end{abstract}

Keywords: Draw-A-Scientist Test (DAST), mixed methods, preservice teachers, science education, visual data 


\section{Preservice Teachers' Images of Scientists: Do Prior Science Experiences Make a Difference?}

In this article, we describe our investigations into the relationship between preservice teachers' prior science experiences (including high school, university, and informal science experiences) and the visual data that we collected using the Draw-A-Scientist Test (DAST). Although we discuss this study more generally elsewhere in a book chapter about the use of visual data (Authors, 2012), here we offer a more comprehensive look at the study design and results. As university instructors of science methods courses for education students, we were interested in our students' images of scientists and subsequently the perceptions of science and scientists they might share with their own students. There is evidence that suggests that students' science experiences primarily occur in classrooms and that teachers have a powerful influence over how their students will view science (Christidou, 2011). For example, Rosenthal (1993) noted that the negative views of scientists held by teachers translated to their teaching behaviours in the classroom. The learning environment established by the classroom teacher can either perpetuate or alter students' conceptions of science and scientists (Carnes, 2009; Christidou, 2011).

The emphasis in science education has shifted away from a 'science for future scientists' pipeline approach towards a 'science for all students' mainstream approach (e.g., Yore, 2011). Consequently, it is even more important that classroom teachers have accurate conceptions of what science is and what scientists do. A 'science for all students' approach to instruction means that science is made more accessible and more relevant for all students. Teachers who hold more accurate conceptions of scientists are likely to send more encompassing messages about who can be a scientist and who can do science. Students who hold negative images of scientists, or who 
are unable to relate to the stereotypical images that are commonly portrayed, are less likely to consider science as an interesting subject or as a career option that they might like to pursue. Figure 1 is an image that was drawn by a preservice teacher in an elementary education program in response to the DAST. The figure shows a scientist who appears approachable but also contains many of the stereotypical elements that are commonly thought to be factors in students electing to avoid science courses and careers.

\section{Insert Figure 1 Here}

We have been teaching elementary and secondary science methods courses at the University of Victoria, Canada since 2006. The context for the study described here is a larger program of research within which we are exploring the effectiveness of specific classroom activities in those methods courses. We selected the DAST as a focus activity for a number of reasons. First, one topic we typically touch upon in our courses is children's images of science and of scientists. We had each been using the DAST, rather informally, with the resulting images initiating discussions about commonly held stereotypes of scientists. In this way, we sought to help preservice teachers understand the importance of challenging their beliefs (Stuart \& Thurlow, 2000). We hoped that the discussions would also help our students become aware of their own conceptualizations of science and scientists. Because classroom teachers are a primary source of information regarding science and scientists (Christidou, 2011; Moseley \& Norris, 2005), the images that our students (preservice teachers) have of scientists will potentially influence their students' perceptions of scientists. The DAST produces visual data, the use of which has been called a non-traditional methodology (Kearney, 2009). However, in education research visual data are often utilized in the areas of art, visual literacy, and media studies. More recently visual data have been gaining credibility in areas of education research as diverse as 
social studies, mathematics, and science (Pederson \& Finson, 2009). Additionally, the DAST is a tool that has been used for more than 30 years, and that usage has been well documented in the science education research literature.

\section{Literature Review}

The DAST was developed as a simple way to assess children's images of scientists. It has been used for more than 30 years with children as young as five (Finson, 2002) and has been called a popular device for teachers wanting to explore their students' images of science (Schibeci, 2006). Pictures obtained through the DAST can be analyzed for stereotypic characteristics; the Draw-a-Scientist Checklist (DAST-C, Finson, Beaver, \& Crammond, 1995) was developed as a tool for reliably identifying and tabulating those characteristics.

The use of the DAST to collect individual's perceptions of science and scientists began with Chambers (1983) who developed the measure based on Mead and Metraux's (1957) compilation of high school students' descriptions of a scientist. The DAST has since been used to explore differences related to K-12 students' age (e.g., Fung, 2002), culture (e.g., Narayan, Park, \& Peker, 2009) and gender (e.g., Losh, Wilke, \& Pop, 2008;Manzoli, Castelfranchi, Gouthier, \& Cannata, 2006;), and has also been used to investigate images drawn by preservice teachers (e.g., McDuffie, 2001; Mosely \& Norris, 1999; Rahm \& Charbonneau, 1997). Some researchers have questioned methodological aspects of the DAST (e.g., Losh et al, 2008) However, the widespread use of the DAST and its frequent appearance in peer-reviewed publications indicates that it is still accepted as a reliable tool for collecting visual data about people's perceptions of scientists.

Age: Studies based upon the use of the DAST have compared differences in drawings created by students of different ages. For example, Fung (2002), working with 675 Chinese 
students aged 7 to 17 , found that the older the student, the more stereotypical characteristics were included in drawings of scientists, suggesting as children grow up, their conceptions of science and scientists become closer to the widely held stereotype. Narayan, Park, and Peker (2009) found similar results in their study of 480 Grades 3 and 7 students from India, South Korea, Turkey, and the United States.

Culture: The DAST has been used by researchers in a number of different countries, including Bolivia and Columbia (Medina-Jerez, Middleton, \& Orihuela-Rabaza, 2010), Hong Kong (Fung, 2002), Italy (Manzoli et al., 2006), and Turkey (Cakmakci, Tosun, Turgut, Orenler, Sengul, \& Top, 2011). Some multinational studies have also utilized the DAST to examine the influence of culture upon perceptions of scientists. Sjøberg (2000) reported on a study involving 9,300 13 year old participants from 21 countries, and noted "systematic" variations in which children from certain countries or regions appeared more able to use drawings as a means of expression. Overall, however, participants depicted scientists as bearded males, wearing lab coats and working in a laboratory surrounded by test tubes. In a smaller scale study of 480 Grades 3 and 7 students from India, South Korea, Turkey, and the United States, Narayan, Park, and Peker (2009) found that although particular aspects of conceptions of science and scientists appeared to be related to culture, the stereotypical characteristics were still evident in students' images of scientists.

Gender: Many studies have examined gender differences in perceptions of scientists. For example, Manzoli et al (2006), working with 48 Grade 3 students from Italy, found that girls were more likely to draw female scientists, but that they often asked permission to do so. In addition, the girls' drawings typically depicted biological or medical sciences; the boys' drawings typically included more technology. In a study of 206 Grades 1, 3, and 5 students from 
the United States, Losh, Wilke, and Pop (2008) also found that girls were more likely than boys to draw female scientists and that girls were more likely to draw figures in which gender could be determined.

Preservice Teachers: Researchers have also used the DAST to explore preservice teachers' images of scientists. Rahm and Charbonneau (1997) found that the drawings of 49 students in a teacher education program contained the stereotypical elements that researchers have noted in drawings produced by young children. Moseley and Norris (1999) examined drawings from 194 preservice and inservice teachers in graduate programs and in early childhood (K-3), elementary (Grades1-8), and secondary (Grades 7-12) programs. They found that the drawings reflected the traditional stereotypes, but that there were some differences by program. For example, only 3 different symbols of research were included in drawings by early childhood majors, while drawings by elementary and secondary majors included more than 20 different symbols.

Studies such as the ones mentioned above suggest the popularity of DAST as a tool for probing student images of scientists. Taken as a whole, results of these studies indicate that regardless of the age, culture, gender, preservice program of the drawer, similar images of scientists are produced: scientists are most often portrayed as middle aged men sporting weird hairdos and wearing lab coats and glasses while working alone in a laboratory setting (see Figure 2). In addition to research related to the differences between groups and their depiction of scientists are studies which suggest that this stereotypical portrayal is susceptible to positive change with intervention (e.g., Finson, 2002; Moseley \& Norris, 1999).

Insert Figure 2 Here

Studies have indicated that children's perceptions of scientists are malleable and that they can be changed by interventions such as having female scientists as classroom visitors, using 
gender-balanced materials, providing opportunities for informal interactions with scientists, and incorporating hands-on inquiry activities (e.g., Finson, 2009; Minogue, 2010; Moseley, \& Norris, 1999). For example, in a quasi-experimental study of 63 Grade 6 Turkish students changes were found in images of scientists after evidence-informed constructivist approaches to instruction that emphasized discussion and reflection were implemented (Cakmakci et al., 2011). Huber and Burton (1995) found that after a semester of hands-on science activities, boys' drawings of scientists became less stereotypic. To a lesser degree, girls' drawings, which were initially less stereotypical than the boys' drawings, also changed. Pre and post DAST results for 24 Turkish children in Grades 6 and 7 who attended ten days summer science camp with male and female scientists suggested that participants' conceptions became less stereotypical (Leblebicioglu, Metin, Yardimci, \& Cetin, 2011). Additionally, preservice teachers' images of scientists and attitudes toward science can be affected by the way science is taught in their teacher education programs (Finson, 2002).

What seems to be missing in the literature is an exploration of whether these interventions and experiences have any lasting effects. We now recognize that there are differences in how scientists are perceived and that we can influence positive changes in these perceptions; however, we do not know how strong these changes might be. Knowing which, if any, prior science experiences significantly influence our preservice teachers' views of scientists could lead to changes in prerequisites for the education program (i.e., in recommended courses and experiences), as well as to changes in the Kindergarten to Grade 12 science curriculum. Furthermore, an increased understanding of preservice teachers' views of scientists would enable science teacher educators to more effectively address stereotypical conceptions and reduce the likelihood of those misconceptions being perpetuated when their students become teachers. 


\section{Research Questions}

The study outlined in this article used the DAST to explore the views of scientists held by preservice students in science methods classes at both the elementary (K-7) and secondary (8-12) levels. We designed this study to help us identify the extent to which our students hold stereotypical views of scientists and to examine how those stereotypes might be influenced by formal and informal prior experiences in science. Our guiding questions were:

1. What differences in visual representations of scientists can be found between student cohorts in different education programs? Are there differences in images drawn by students in the regular elementary program and students in the post degree elementary program? Are there differences in images drawn by students planning to become elementary teachers and students planning to become secondary teachers?

2. If there are differences, to what degree might those differences be related to preservice teachers' prior science experiences?

We hypothesized that there would be differences between student cohorts and that those differences would be related to the extent of students' prior science experiences. Further, we anticipated that students with more formal science backgrounds (e.g., undergraduate degree in science and/or additional science experiences) would generate less stereotypical images of scientists while their peers with more limited or more informal science experiences would generate more stereotypical images.

\section{Data Collection and Analysis}

We took a mixed methods approach to our investigation of preservice teachers' images of scientists and how those images might be affected by prior experiences. We utilized a Triangulation Design, the most common application of mixed methods research (Creswell \& 
Plano Clark, 2007), that equally emphasized qualitative and quantitative approaches to collecting and analyzing visual data in our investigation. The resulting data were integrated to provide a better understanding of our research question than either quantitative data or qualitative data might reveal (Creswell \& Plano Clark, 2007).

We focused on visual data in this study because we believed that drawings would yield information about our students" "deeply embedded ideas" (Finson, 2009, p. 61) that might not be revealed in written or spoken responses. We selected the DAST as the most appropriate tool with which to begin to answer our first set of research questions because it is a well-established tool for using visual data to investigate ideas about science and scientists. To help us address our second research question, we used written data obtained from a questionnaire, created for this study, that focused on participants' formal and informal science experiences. Participants draw a scientist, and resulting images can then be analyzed for stereotypic characteristics that can be reliably identified and tabulated using the Draw-a-Scientist Checklist (DAST-C, Finson, Beaver, \& Crammond, 1995). Higher scores on the DAST-C indicate highly stereotypical images, while lower scores indicate less stereotypical representations of scientists.

\section{Participants}

The participants in this study were students in three different education cohorts who were enrolled in either elementary or secondary science methods courses that were offered over 13 consecutive weeks at the University of Victoria, Canada, between 2008 and 2010. The students were either a) Regular Program education students for whom a B.Ed. in elementary education would be a first degree; b) Post Degree Program (PDP) students for whom a B.Ed. in elementary education would be a second degree; or c) PDP students for whom a B.Ed. in secondary education would be following a B.Sc., an M.Sc., or in rare cases, a Ph.D. in science. We 
collected complete sets of responses from 165 students: 51 students in the regular program, 76 students in the PDP elementary program, and 38 students in the PDP secondary program. Approximately $90 \%$ of the participants were female, a percentage that accurately reflected the characteristics of students in the education program.

\section{Procedure}

All data were collected at the start of term and analyzed after the course had concluded. To maintain confidentiality, during the first class of the term, while we were out of the classroom, a research assistant gave the students a scripted presentation about a larger study of classroom activities that encompassed the DAST research. The assistant collected the consent forms, placed them in a sealed envelope, and kept them in a locked filing cabinet until after we had submitted the final grades for the course. In this way, we did not know which students had consented to participate in the study while we were in a power-over position of instructor and student, thus avoiding any potential bias towards participants or nonparticipants.

After the consent forms had been collected, we returned to the classroom, handed out unlined pieces of $81 \frac{1}{2}$ X 11 paper, and gave the prompt: In the next 10 minutes, please draw a scientist. No other guidelines or restrictions were given. After students finished drawing, they were asked to label their drawings with an identifying word, phrase, or image that would allow us to match up participants' work without revealing participants' identities. For example, in this particular study, we paired the DAST image with a completed questionnaire. The short questionnaire, shown in Appendix A, addressed students' previous science experiences at the high school, college, and university level, as well as informal experiences such as summer science camp.

\section{Analysis}

We adapted the DAST-C (Finson, et al., 1995) to create a checklist for scoring our preservice teachers' drawings. We began by using the original DAST-C to score a random 
sample of ten images and found that we were not able to determine the ethnicity of the people in any of the images. Therefore, we eliminated ethnicity from our checklist. As we continued scoring, we noted that when we scored the presence of an indication of danger, those indications were often fumes of some sort, so we added fumes to our checklist as a specific item. We also noted that question marks were often used to depict curiosity or wonder. Our final checklist is shown in Appendix B. We used this checklist to score all images independently. Inter-rater reliability was calculated with a point-by-point agreement ratio (Kazdin, 2011) which allowed us to review response categories instead of total agreement. The mean total point-by-point agreement was calculated to be $95 \%$ (ranging from 90 to 100\%). Differences were discussed until we reached consensus for all images.

Table 1 shows the number and percentage of participants who included specific elements in their drawings of scientists such as the physical appearance of the scientist, the presence of scientific knowledge indicators, gender, and work place. Without exception, close to or more than half of students across all programs produced stereotypical images of scientists that included lab coats, wild hairdos, glasses, and scientific equipment for both the physical appearance and scientific knowledge categories. No clear differences between programs were immediately apparent in these data for individual elements, so we calculated category scores for physical appearance and scientific knowledge in an effort to reveal any general trends that might exist.

Insert Table 1 Here

Overall scores for the categories of physical appearance and scientific knowledge were based on the indicator elements shown in Table 1. Some items on our modified DAST-C such as light bulbs or mythic stereotypes were not included in our statistical analysis because the number 
of drawings containing those items was too small for valid and reliable calculations. One point was scored for the presence of each indicator in a category so scores for physical appearance and scientific knowledge could range from 0 to 4 . For example, the drawing in Figure 1 received a physical appearance score of 3 and a scientific knowledge score of 3, while the drawing in Figure 2 received a physical appearance score of 4 and a scientific knowledge score of 1 . We identified two other elements that were evident in enough drawings that we could compare results statistically. Work location was scored as inside, outside, or unknown and gender was scored as male, female, or unknown. The drawing in Figure 1 was scored inside and unknown, while the drawing in Figure 2 was scored inside and male.

Trends across groups for categorical physical appearance and scientific knowledge scores can be seen in Table 2. Participants in the regular elementary program included a greater number of indicator elements for physical appearance and scientific knowledge than the either the PDP elementary or PDP secondary participants. This trend continued with the regular elementary program participants drawing more male scientists and more scientists working indoors than the PDP elementary or PDP secondary participants (see Table 3).

Insert Table 2 Here

Insert Table 3 Here

We analyzed the completed questionnaires using an open coding procedure (Flick, 2002) which resulted in the development of categories (codes) for each question. We coded participants' responses to the questions about formal science experiences (i.e., what science courses did you take in high school and/or university?) into six categories. These included Some $H S$, a listing of science courses up to and including Grade 10; Grade 11/12, chemistry, biology, physics, or other science courses listed as being taken in grades 11 and/or 12; EOS or AST, any 
mention of taking university survey courses in Earth and Ocean Sciences or Astronomy (these are typically taken by pre-education students to satisfy the basic requirements for admission into the elementary program); $U / G$, responses indicating a completed undergraduate degree in any subject excluding science; $B S c$, responses that indicated a completed undergraduate degree in any science; and MSc Plus, responses indicating completion of a graduate degree in science. Finally, each participant's paired image and questionnaire were analyzed to examine the influence of science experiences on stereotypes of scientists. Participants' responses to the question about informal science experiences were coded as yes or no; more specific categories could not be developed because of a limited number of responses.

Table 4 provides an overview of participants' science experiences, both formal and informal, as revealed by their responses on the questionnaire. Students in the regular elementary program tended to have more limited undergraduate science experiences, with their experience typically consisting of one introductory survey course in Earth and Ocean Sciences or Astronomy. Students in the post degree programs reported taking a wider variety of science courses and also tended to recall having had more informal science experiences.

\section{Insert Table 4 Here}

Because our data were both categorical and ordinal, we used contingency tables (cross tabulations) as a preliminary means of evaluating the relationships between students' experiences and their images of scientists as revealed by the DAST. Data from the adapted DAST-C and the science questionnaires were entered into PASW SPSS 18 (IBM SPSS Inc., 2010) and were analysed using Kendall's Tau-c and chi-square $\left(\chi^{2}\right)$, which provide summary measures of association. Assumptions of single item entry and expected frequencies greater than 5 per cell were met. 
Table 5 is a contingency table that reveals trends in the strength of the association between the program a student was enrolled in (i.e., Regular Elementary $(n=51)$, Post Degree Elementary $(n=76)$ and Post Degree Secondary $(n=38))$ and the categorical score for physical appearance. If our initial hypothesis was correct, the percentage values would increase from left to right and from top to bottom (i.e., the highest values would be in the cells at the top right and the bottom left). The larger the difference in percentages, the greater the relationship suggested. The data in Table 5 suggest that more students in the regular elementary program received higher scores for physical appearance on their drawings of scientists and more students in the PDP secondary program had lower scores.

Insert Table 5 Here

Kendall's Tau-c $=0.172 ; p<.05 ; \mathrm{n}=165$ for this association, and it may be interpreted in the same way as a correlational coefficient. Thus, according to Kendall's Tau-c there is a small association between science background and indicators of physical appearance for participants drawn scientists. Those students who reported more science education tended to include fewer stereotypical indicators in their drawings of scientists. Figure 3 shows how the stereotypical appearance scores varied depending on the education program in which the students are enrolled.

Insert Figure 3 Here

The question of association between prior science knowledge and physical appearance scores on the DAST-C was further explored by collapsing data to a nominal level. In an effort to see if information on the a priori hypothesis could be further elaborated, we collapsed categories for analysis. In this case, the students were split into two groups: students who held a prior degree and students who did not (i.e., students in the regular elementary program vs. students in the Post Degree Program - elementary or secondary). Similarly, the physical appearance scores 
on the DAST-C was median split into lower scores (0 and 1) and higher scores (2, 3 and 4$)$. The collapsed categories, shown in Table 6 and Figure 4 , are significantly different $\left(\chi^{2}=5.05, p<.05\right)$.

Insert Table 6 Here

Insert Figure 4 Here

Similarly, we analyzed participants' depictions of science knowledge as indicated by scores on the modified DAST-C, which are shown in Table 7. In this instance we conducted the analysis as an exploratory analysis instead of identifying an a priori hypothesis. From the values in Table 7 it appeared that the independent category of program did not significantly impact upon indications of science knowledge in participants' drawings of scientists. The majority of scores for the category of science knowledge were between 1 and 2 across all groups. The nonsignificant chi-squared value $\left(\chi^{2}=13.26, p=.103\right)$ supported this initial impression of no significant association. Because the results were not significant, a graph of these data is not provided.

\section{Insert Table 7 Here}

\section{Discussion}

The two guiding questions for this study were: (1) What differences in visual representations of scientists can be found between the students in different education programs; and, (2) How are those differences related to preservice teachers' prior science experiences? We hypothesized that students with broader science backgrounds (e.g., formal science experiences such as an undergraduate degree in science) would generate less stereotypical images of scientists while their peers with fewer formal science experiences would generate more stereotypical images. For the purposes of our analysis, we selected the physical appearance score as the major indication of a stereotypical image of a scientist. 
Our first hypothesis that students with greater previous science experience at both the secondary and post-secondary level would create visual representations of scientist that were significantly less stereotypical than representations created by students with lesser previous science experience was supported according to our analysis of the visual data using the modified DAST-C. Additionally, students with previous university degrees - regardless of the area that the degrees were in - tended to include fewer stereotypical indicators for physical appearance. However, the results indicated that science background only explains less than $4 \%$ of the variance in physical appearance scores. Obviously there are other factors such as societal and/or cultural influence that were not captured in our analysis.

When we tried to extend our analysis to the symbols of science knowledge that were included in images of scientists there appeared to be no significant association between the number of symbols and the extent of formal science background. We speculate that this lack of a significant association may be due to the lower frequency of such symbols appearing in the drawings across all groups, as compared to the more numerous inclusions of physical characteristics.

Our findings are in general agreement with other studies that have examined the presence of stereotypical elements in the visual representations of scientists, such as studies using the DAST with preservice teachers ranging from early childhood educators to secondary teachers (Moseley, \& Norris, 1999) and studies involving computer science and psychology undergraduate students (Thomas, Henley, \& Snell, 2006). However, the results of our study suggested what these other studies did not - a significant difference between students with more formal science backgrounds (i.e., at least an undergraduate B.Sc.), who depicted scientists as less stereotypical and students with less extensive formal science experiences (e.g., only high school 
courses or introductory university courses), who depicted scientists that were more stereotypical in appearance.

Additionally, and perhaps noteworthy when considering the prerequisites for preservice teachers, we obtained a significant result indicating that preservice teachers who have previously completed a university degree, regardless of the subject, generate images of scientists that have fewer stereotypical physical characteristics compared to preservice teachers who do not have a previous degree and are pursuing education as their first degree. Together, these results suggest that both intensive formal education in science (i.e., completion of a B.Sc. or M.Sc.) and more comprehensive prior education (i.e., completion of a bachelor's degree in any area) can mitigate the stereotypical qualities of preservice teachers' images of scientists.

\section{Concluding Remarks}

Visual data are gaining wider acceptance within the science education community and beyond because this mode of data can allow insights that might not be obtained using written or verbal data. The DAST and the DAST-C are well documented tools that allow for the collection and analysis of visual data in the form of images of scientists. In general, studies using the DAST indicate that the image of a middle-aged man, who wears a lab coat and glasses, has a crazy hairdo, and works in isolation in a laboratory is a widely held stereotype of a scientist. The stereotype can, however, be addressed through a range of interventions that include science activities and experiences that begin in elementary school and continue throughout teacher education programs. Interventions at the elementary classroom level include visiting female scientists and hands-on inquiry activities, while interventions at the university level would seem to include a degree requirement for entry into an education program. Once in an education 
program, students should have opportunities to reflect on their conceptions of science and scientists.

The motivation for this study came out of our ongoing practices in the science methods classroom. We are both interested in preservice teachers' science knowledge and beliefs and how these concepts might influence their development as teachers. Among other things, we both seek to dispel some of the inaccurate stereotypes of scientists that preservice teachers typically hold. The visual data that we collected during this study have given us a clearer understanding of just what those stereotypic images might be for students in each of three specific education programs and for students with specific backgrounds and experiences. Our approach to teaching science methods includes helping our students to see themselves as science teachers by encouraging them to conceptualize science as an activity that they and their own students can engage in collaboratively, indoors and out, regardless of gender, ethnicity, or age. 


\section{References}

Authors. (in press)

Cakmakci, G., Tosun, O., Turgut, S., Orenler, S., Sengul, K., \& Top, G. (2011). Promoting an inclusive image of scientists among students: Towards research evidence-based practice. International Journal of Science and Mathematics Education, 9, 627-655.

Carnes, G. N. (2009). Interpreting drawings of preservice teachers. In J. E. Pederson \& K. D. Finson (Eds.), Visual data: Understanding and applying visual data to research in education (pp. 79-92). Rotterdam, The Netherlands: Sense.

Chambers, D. W. (1983). Stereotypic image of the scientist: The Draw-A-Scientist test. Science Education, 67(2), 255-265.Christidou, V. (2011). Interest, attitudes and images related to science: Combining students' voices with the voices of school science, teachers, and popular science. International Journal of Environmental and Science Education, 6 (2), 141-159.

Creswell, J., \& Plano Clark, V. (2007). Designing and conducting mixed methods research. Thousand Oaks, CA: Sage.

Finson, K. D. (2002). Drawing a scientist: What we do and do not know after fifty years of drawings. School Science and Mathematics, 102(7), 335-345.

Finson, K. D. (2009). What drawings reveal about perceptions of scientists: Visual data operationally defined. In J. E. Pederson \& K. D. Finson (Eds.), Visual data: Understanding and applying visual data to research in education (pp. 59-77). Rotterdam, The Netherlands: Sense.

Finson, K. D., Beaver, J. B., \& Cramond, B. L. (1995). Development and field test of a checklist for the Draw-A-Scientist Test. School Science and Mathematics, 95(4), 195-205. 
Flick, U. (2002). An introduction to qualitative research (2nd ed.). Thousand Oaks, CA: Sage Publications.

Fung, Y. Y. H. (2002). A comparative study of primary and secondary school students' images of scientists. Research in Science and Technological Education, 20(2), 199-213. DOI: $10.1080 / 0263514022000030453$

IBM SPSS Inc. (2010). PASW STATISTICS 18.0 Command Syntax Reference. SPSS Inc., Chicago, IL.

Kazdin, A. E. (2011). Single-case research design: Methods for clinical and applied settings $\left(2^{\mathrm{nd}}\right.$ ed.). Oxford, UK: Oxford University.

Kearney, K. (2009). Participant-generated visual data: Drawing out emotions. In J. E. Pederson \& K. D. Finson (Eds.), Visual data: Understanding and applying visual data to research in education (pp. 51-58). Rotterdam, The Netherlands: Sense.

Leblebicioglu, G., Metin, D., Yardimci, E., \& Cetin, P. S. (2011). The effect of informal and formal interaction between scientists and children at a science camp on their images of scientists. Science Education International, 22(3), 158-174.

Losh, S. C., Wilke, R., \& Pop, M. (2008). Some methodological issues with "Draw a Scientist Tests" among young children. International Journal of Science Education, 30(6), 773-792, doi: $10.1080 / 09500690701250452$

Manzoli, F., Castelfranchi, Y., Gouthier, D., \& Cannata, I. (2006). Children's perceptions of science and scientists. Proceedings of the $9^{\text {th }}$ International Conference on Public Communication of Science and Technology. Seoul, Available at http://www.pcst2006.org/ McDuffie, T. E. (2001). Scientists: Geeks \& nerds? Science and Children, 38(8), 16-19. 
Mead, M., \& Metraux, R. (1957). Image of the scientist among high school students. Science, 126(3270), 384-390.

Medina-Jerez, W., Middleton, K. V., \& Orihuela-Rabaza, W. (2010). Using the DAST-C to explore Columbian and Bolivian students' images of scientists. International Journal of Science and Mathematics, 9, 657-690.

Minogue, J. (2010). What is the teacher doing? What are the students doing? An application of the Draw-a-Science-Teacher test. Journal of Science Teacher Education, DOI: $10.1007 / \mathrm{s} 10972-009-9170-7$

Moseley, C., \& Norris, D. (1999). Preservice teachers' views of scientists. Science and Children, $36(2), 50-53$.

Narayan, R., Park, S., \& Peker, D. (2009). Sculpted by culture: Students' embodied images of scientists. Proceedings of the 3rd International Conference to Review Research on Science, TEchnology and Mathematics Education (pp. 45-51). Mumbai, India. Available at http://cvs.gnowledge.org/episteme3/proc_pdf.php

Odell, M. R. I., Hewitt, P., Bowman, J., \& Boone, W. J. (1993). Stereotypical images of scientists: A cross-age study. Paper presented at the $41^{\text {st }}$ annual national meeting of the National Science Teachers Association, Kansas City, MO.

Pedersen, J. E., \& Finson, K. D. (2009). Visual data: Understanding and applying visual data to research in education. Rotterdam, The Netherlands: Sense.

Rahm, J., \& Charbonneau, P. (1997). Probing stereotypes through students' drawings of scientists. American Journal of Physics, 65(8), 774-778.

Rampal, A. (1992). Images of science and scientists: A study of school teachers' views I. Characteristics of scientists. Science Education, 76(4), 415-436. 
Rosenthal, D. B. (1993). Images of scientists: A comparison of biology and liberal arts majors. School Science and Mathematics, 93(4), 212-216.

Schibeci, R. (2006). Student images of scientists: What are they? Do they matter? Teaching Science, 52(2), 12-16.

Stuart, C. \& Thurlow, D. (2000). Making it their own: Preservice teachers' experiences, beliefs and classroom practice. Journal of Teacher Education, 51(2), 113-121.

Sumrall, W. J. (1995). Reasons for the perceived images of scientists by race and gender of students in grades 1-7. School and Science Mathematics, 95(2), 83-90.

Thomas, J. A., Pedersen, J. E., \& Finson, K. D. (2001). Validating the Draw-A-Science-TeacherTest checklist (DASTT-C): Exploring mental models and teacher beliefs. Journal of Science Teacher Education, 12(3), 295-310.

Thomas, M. D., Henley, T. B., \& Snell, C. M. (2006). The Draw a Scientist Test: A different population and a somewhat different story. College Student Journal, 40(1), 140-148.

Yore, L. D. (2011). Foundations of scientific, mathematical, and technological literaciesCommon themes and theoretical frameworks. In In L. D. Yore, E. Van der Flier-Keller, D. W. Blades, T. W. Pelton, \& D. B. Zandvliet (Eds.) Pacific CRYSTAL Centre for Science, Mathematics, and Technology Literacy: Lessons Learned (pp. 23-44). Rotterdam, The Netherlands, Sense Publishers. 
Appendix A

Science Experiences Questionnaire

Directions:

1. Put your identifying word, phrase, or image in the box.

2. Answer the questions below, adding as many details as possible.

Questions:

1. What science courses did you take in high school? If possible, include details such as how many years ago that was, topics covered, or most memorable lesson.

2. What college or university science courses have you taken? Again, include details.

3. What informal science experiences have you had? (Examples: summer camps, work experience). Please indicate the approximate duration of the experience and how many years ago the experience occurred. 


\section{Appendix B}

Adapted Scoring Checklist based on the DAST-C

\begin{tabular}{ll}
\hline Category & Item \\
\hline Physical & Lab coat \\
Appearance & Eyeglasses or Goggles \\
& Facial hair \\
& Wild hairdo \\
\hline Scientific & Research instruments (specify \\
Knowledge & types and sizes) \\
& Symbols of knowledge (specify) \\
& Technology \\
& Scientific captions \\
\hline Gender & a. male \\
& b. female \\
& c. indeterminate \\
\hline Work & a. indoors \\
environment & b. outdoors \\
& c. indeterminate \\
\hline Age & a. Middle aged or elderly \\
& b. indeterminate \\
& c. child \\
\hline Other & Indications of danger \\
& a. fumes \\
& Light bulbs \\
& Mythic stereotypes \\
& Indications of secrecy \\
& Question marks \\
& Other comments \\
\hline
\end{tabular}




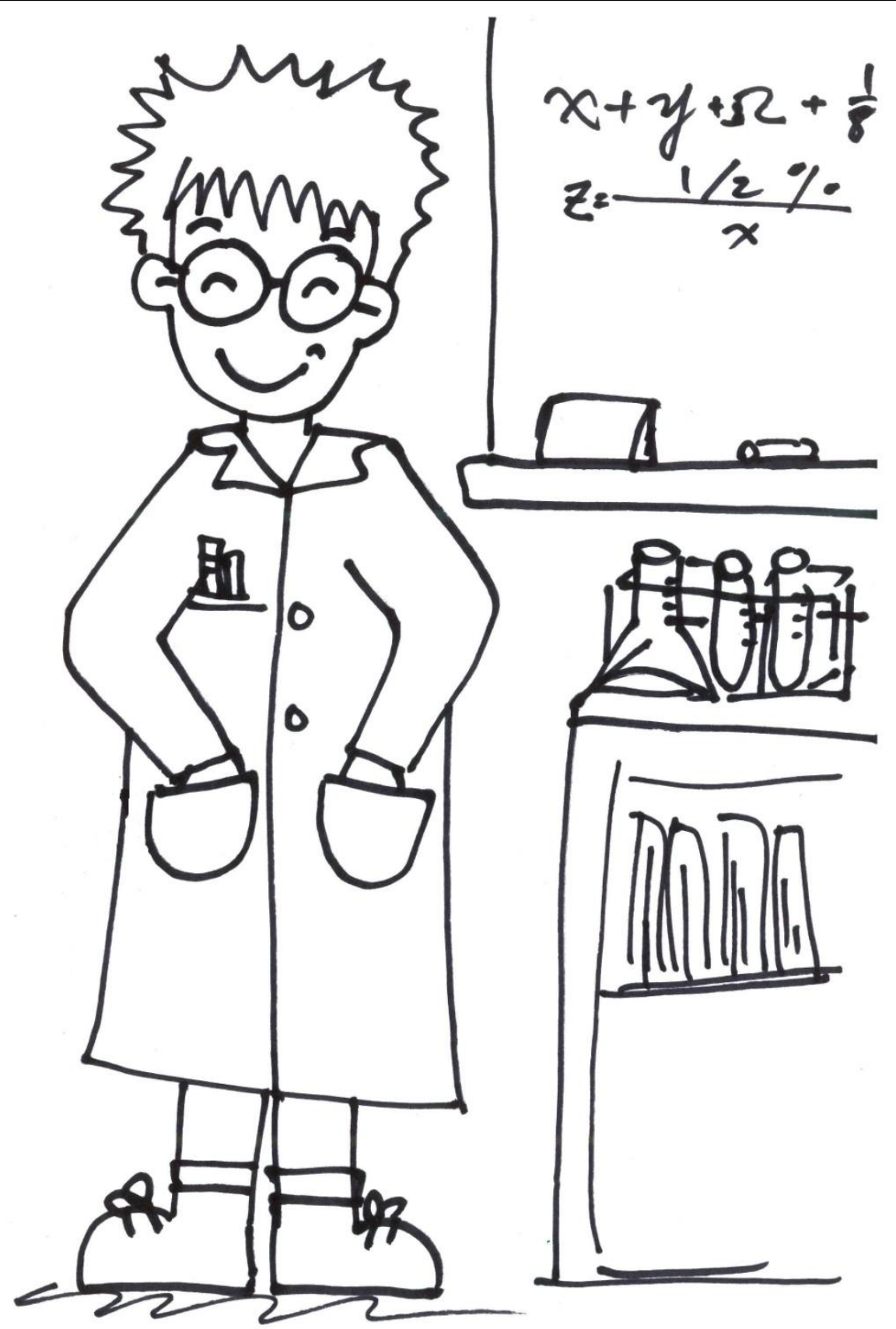

Figure 1. A figure drawn by a pre-service teacher in response to the DAST. The scientist is of indeterminate gender, but is wearing a lab coat and glasses, has a quirky hairdo, and is working in a laboratory setting. 


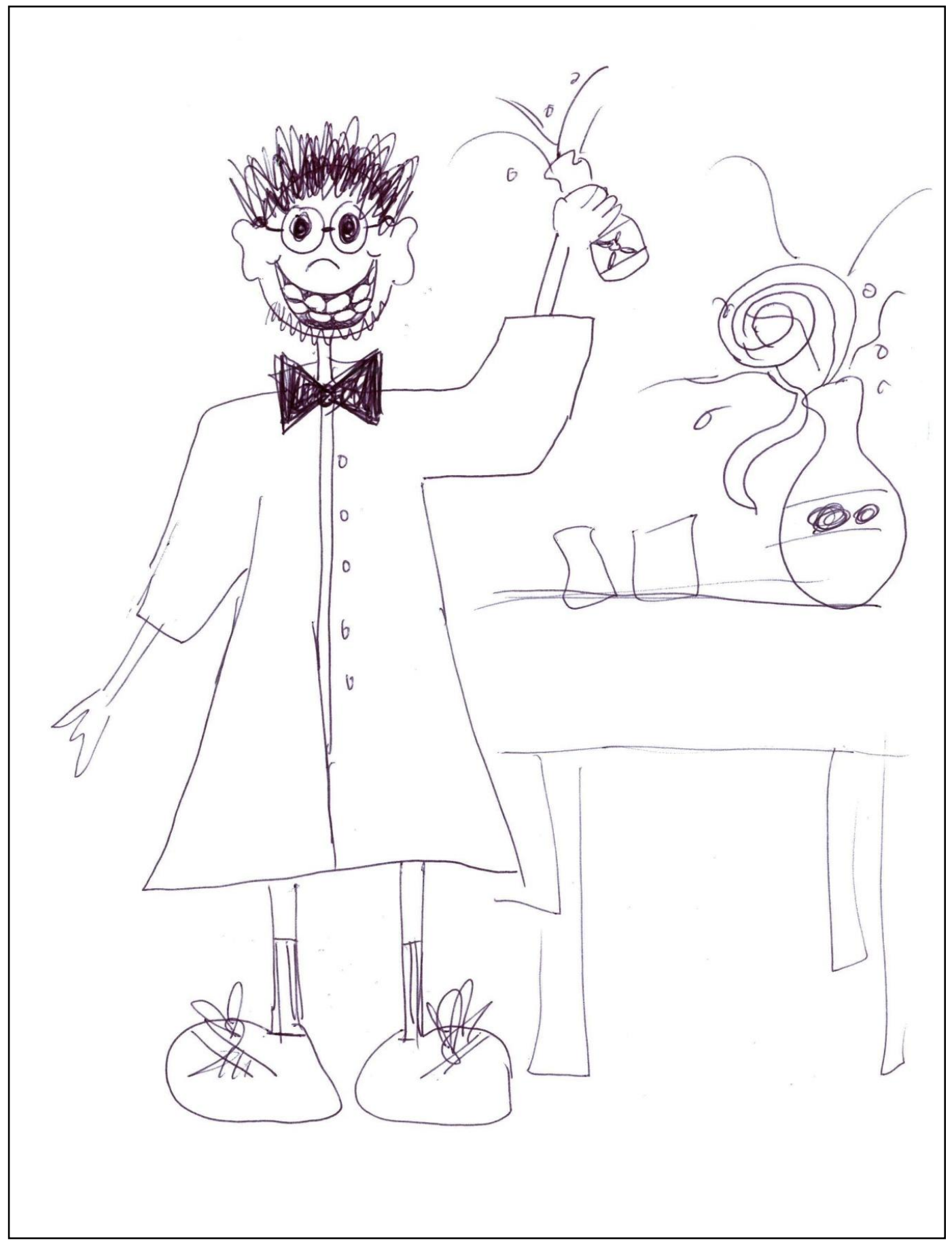

Figure 2. A stereotypical image drawn by a preservice teacher in response to the DAST. 


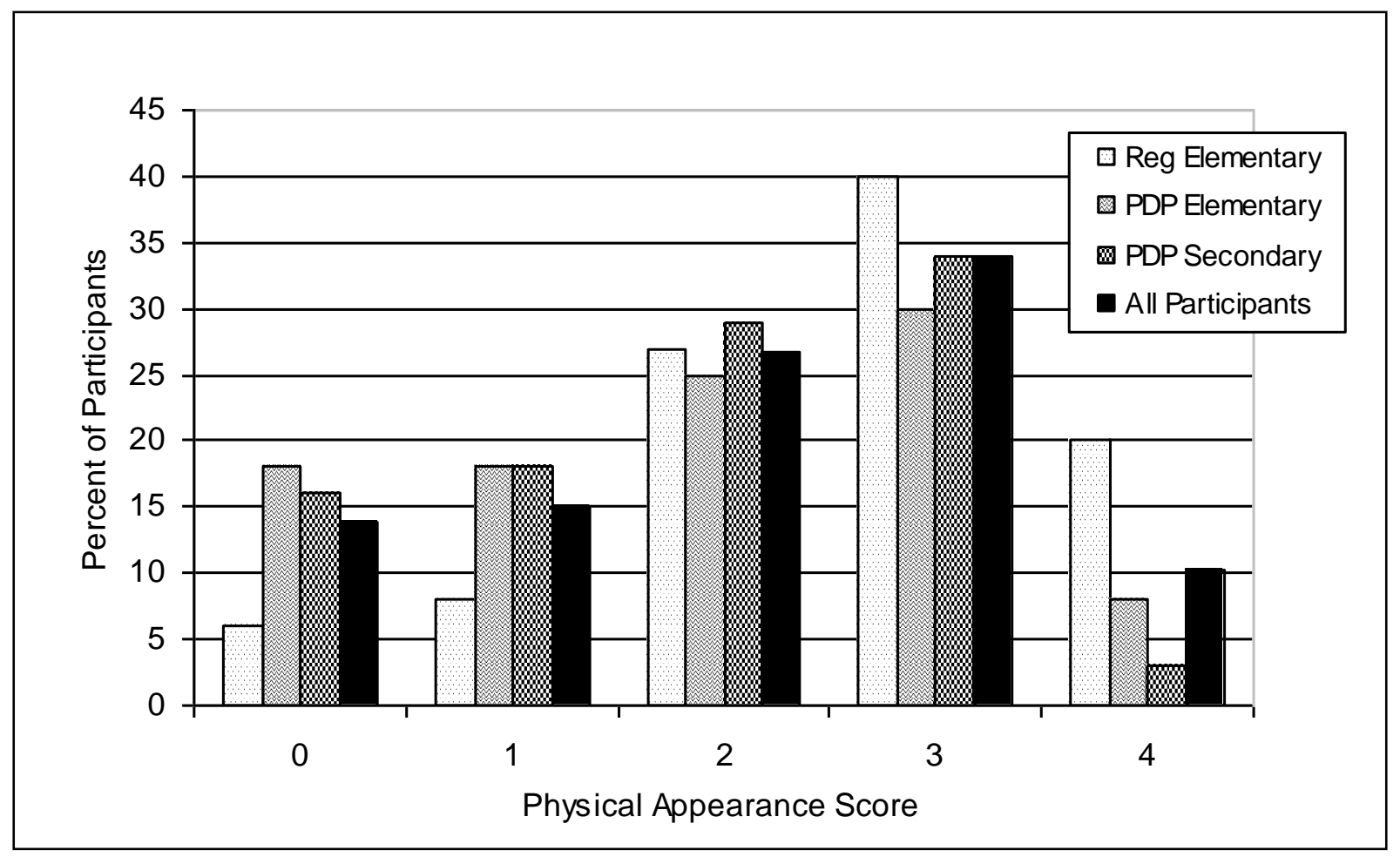

Figure 3. Physical appearance scores on the DAST for participants from three education programs. 


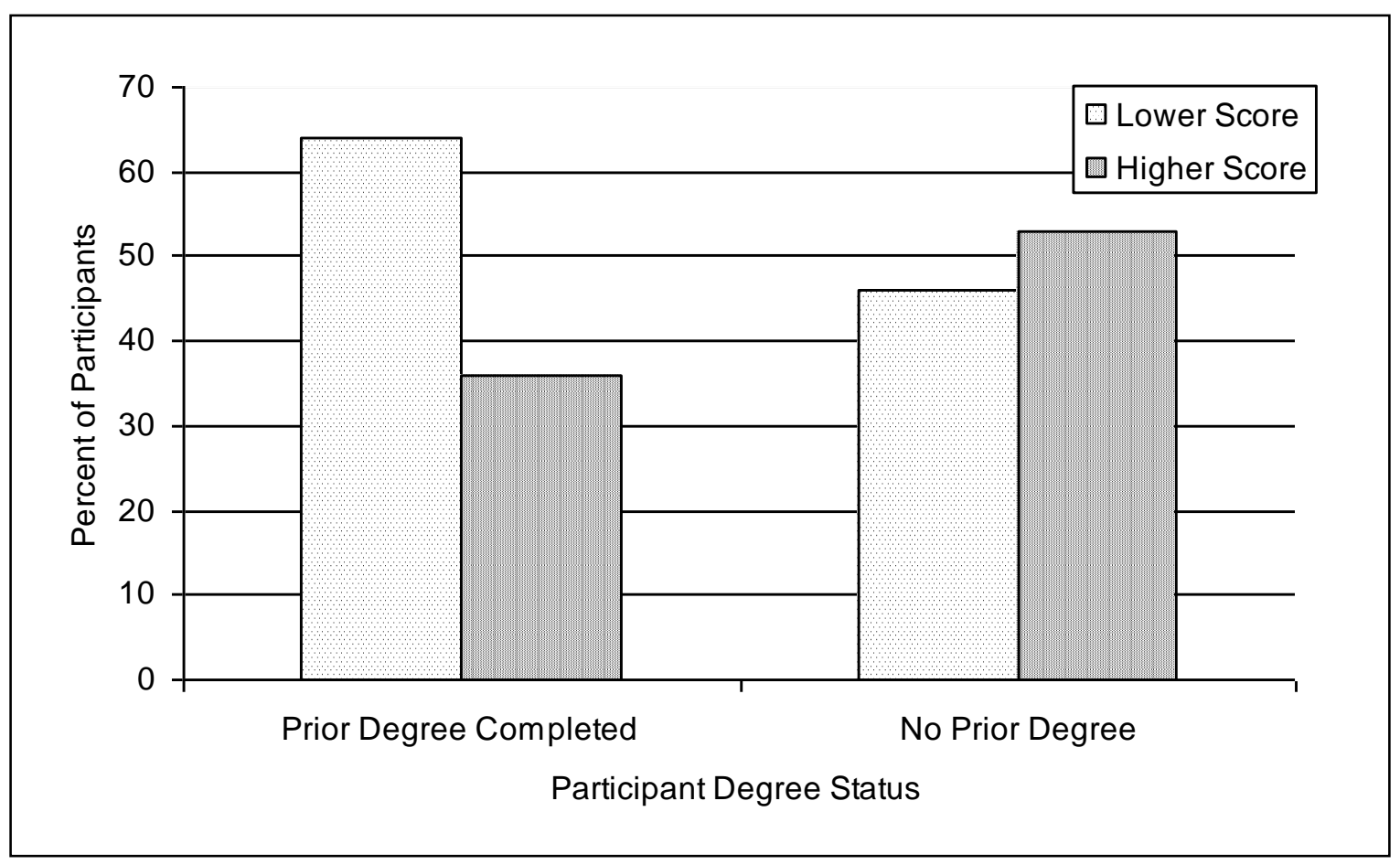

Figure 4. Collapsed physical appearance scores on the DAST, arranged by degree status of participants. 
Table 1

Preservice Teachers' Scores for Selected Elements on the Modified DAST-C: Total and by Program

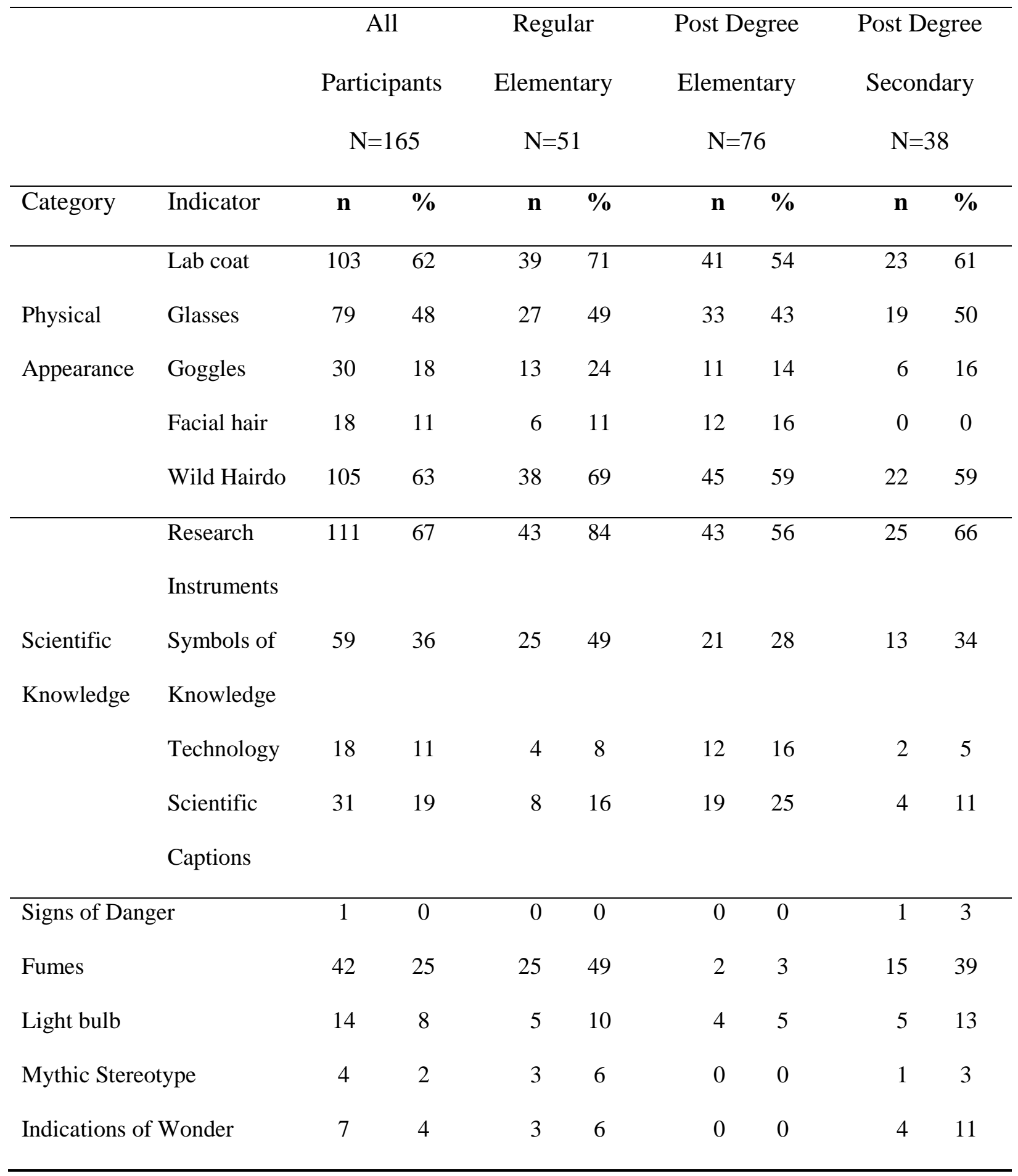


Table 2

DAST Category Scores for Appearance and Knowledge, by University Program of Participant

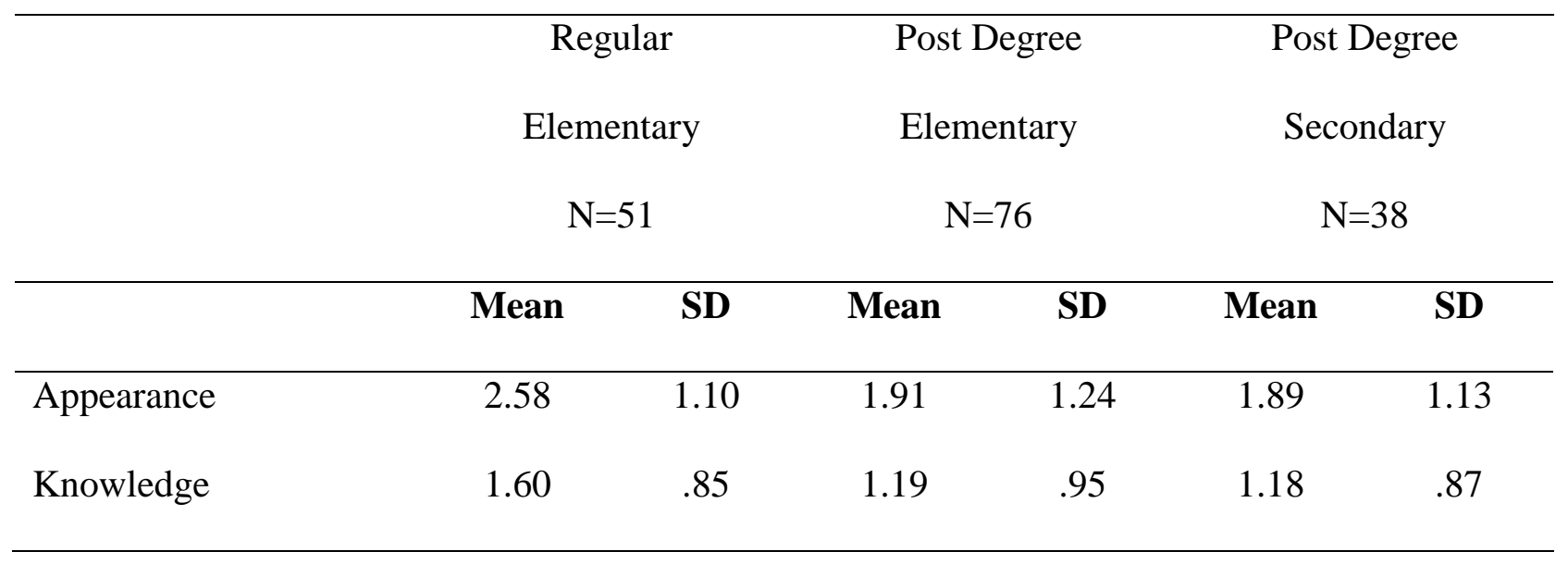


Running head: PRE-SERVICE TEACHERS' IMAGES OF SCIENTISTS

Table 3

DAST Scores for Location and Gender, by University Program of Participant

\begin{tabular}{|c|c|c|c|c|c|c|c|}
\hline & & & & & & & \\
\hline & & & & & & & \\
\hline & & & & & & & \\
\hline & & $\mathbf{n}$ & $\%$ & $\mathbf{n}$ & $\%$ & $\mathbf{n}$ & $\%$ \\
\hline Location & Indoors & 23 & 45.1 & 11 & 14.4 & 6 & 15.8 \\
\hline & Outdoors & 0 & 0 & 15 & 19.7 & 2 & 5.2 \\
\hline & Unknown & 51 & 54.9 & 50 & 65.8 & 30 & 78.9 \\
\hline Gender & Male & 23 & 45.1 & 6 & 7.9 & 5 & 13.2 \\
\hline & Female & 8 & 15.7 & 14 & 18.4 & 10 & 26.3 \\
\hline & Unknown & 20 & 39.2 & 56 & 73.7 & 23 & 60.5 \\
\hline
\end{tabular}


Table 4

Science Experiences of Preservice Teachers in Three Different University Programs, as Revealed by Questionnaire Responses

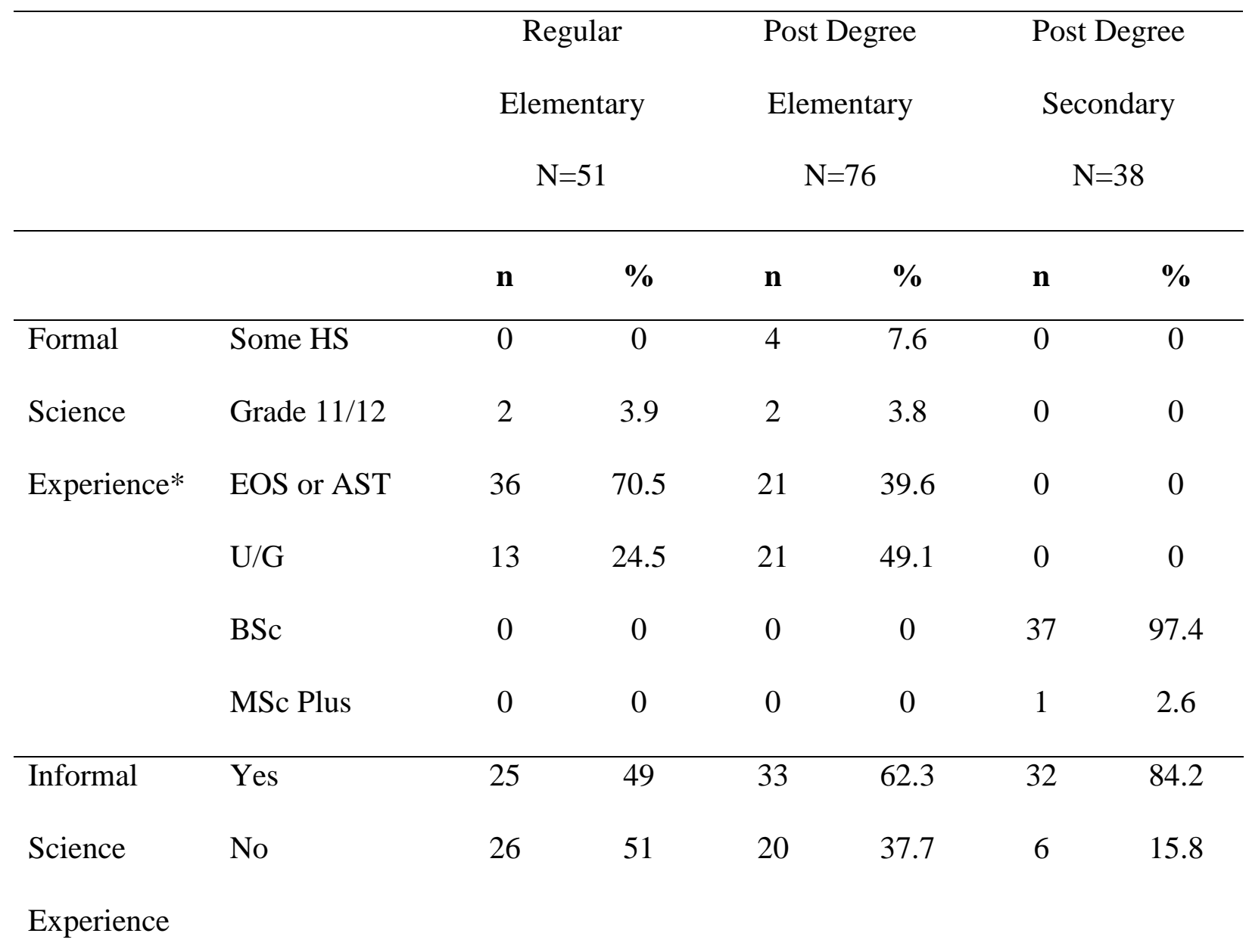

*Some HS = some high school; Grade 11/12 = Grade 11/12; EOS or AST = survey course in Earth and Ocean Science or Astronomy; $\mathrm{U} / \mathrm{G}=$ completed undergraduate degree (not science); $\mathrm{BSc}=$ completed undergraduate degree in science; $\mathrm{MSc}=$ masters degree or higher in science 
Running head: PRE-SERVICE TEACHERS' IMAGES OF SCIENTISTS

Table 5

Modified DAST-C Stereotypical Physical Appearance Scores for Preservice Teachers' Images of Scientists According to Program

\begin{tabular}{|c|c|c|c|c|c|c|c|c|}
\hline & \multirow{2}{*}{\multicolumn{2}{|c|}{$\begin{array}{c}\text { Regular } \\
\text { Elementary }\end{array}$}} & \multirow{2}{*}{\multicolumn{2}{|c|}{$\begin{array}{l}\text { Post Degree } \\
\text { Elementary }\end{array}$}} & \multirow{2}{*}{\multicolumn{2}{|c|}{$\begin{array}{l}\text { Post Degree } \\
\text { Secondary }\end{array}$}} & \multirow{2}{*}{\multicolumn{2}{|c|}{ All Participants }} \\
\hline & & & & & & & & \\
\hline & $\mathbf{n}$ & $\%$ & $\mathbf{n}$ & $\%$ & $\mathbf{n}$ & $\%$ & $\mathbf{n}$ & $\%$ \\
\hline 0 & 3 & 6 & 14 & 18 & 6 & 16 & 23 & 13.9 \\
\hline 1 & 4 & 8 & 14 & 18 & 7 & 18 & 25 & 15.1 \\
\hline 2 & 14 & 27 & 19 & 25 & 11 & 29 & 44 & 26.7 \\
\hline 3 & 20 & 40 & 23 & 30 & 13 & 34 & 56 & 33.9 \\
\hline 4 & 10 & 20 & 6 & 5 & 1 & 3 & 31 & 10.3 \\
\hline $\mathrm{N}$ & 51 & 100 & 76 & 100 & 38 & 100 & 165 & 100 \\
\hline
\end{tabular}


Running head: PRE-SERVICE TEACHERS' IMAGES OF SCIENTISTS

Table 6

Collapsed Physical Appearance Scores According to Participant Degree Status

\begin{tabular}{lcccccc}
\hline & Prior Degree Completed & \multicolumn{2}{c}{ No Prior Degree } & \multicolumn{2}{c}{ All Participants } \\
& $\mathbf{n}$ & $\mathbf{\%}$ & $\mathbf{n}$ & $\mathbf{\%}$ & $\mathbf{n}$ & $\mathbf{\%}$ \\
\hline Lower & 54 & 64 & 38 & 46 & 92 & 56 \\
Score & & & & & \\
Higher & 30 & 36 & 43 & 53 & 73 & \\
Score & & & & & \\
\hline Total & 84 & 100 & 81 & 100 & 165 & 100 \\
\end{tabular}


Running head: PRE-SERVICE TEACHERS' IMAGES OF SCIENTISTS

Table 7

Modified DAST-C Stereotypical Scientific Knowledge Scores for Preservice Teachers' Images of Scientists, According to Education Program

\begin{tabular}{|c|c|c|c|c|c|c|c|c|}
\hline \multirow[b]{3}{*}{ Score } & \multicolumn{2}{|c|}{ Regular } & \multicolumn{2}{|c|}{ Post Degree } & \multicolumn{2}{|c|}{ Post Degree } & \multicolumn{2}{|c|}{ All Participants } \\
\hline & \multicolumn{2}{|c|}{ Elementary } & \multicolumn{2}{|c|}{ Elementary } & \multicolumn{2}{|c|}{ Secondary } & & \\
\hline & $\mathbf{n}$ & $\%$ & $\mathbf{n}$ & $\%$ & n & $\%$ & $\mathbf{n}$ & $\%$ \\
\hline 0 & 3 & 6 & 22 & 29 & 9 & 24 & 34 & 21 \\
\hline 1 & 22 & 43 & 23 & 30 & 15 & 39 & 60 & 36 \\
\hline 2 & 19 & 37 & 25 & 33 & 12 & 32 & 56 & 34 \\
\hline 3 & 6 & 12 & 6 & 8 & 2 & 5 & 14 & 8 \\
\hline 4 & 1 & 2 & 0 & 0 & 0 & 0 & 1 & 1 \\
\hline $\mathrm{N}$ & 51 & 100 & 76 & 100 & 38 & 100 & 165 & 100 \\
\hline
\end{tabular}

